\title{
A granular tabu search for the refrigerated vehicle routing problem with homogeneous fleet
}

\author{
John Willmer Escobara*, José Luis Ramírez Duque ${ }^{\mathrm{b}}$ and Rafael García-Cáceres ${ }^{\mathrm{c}}$
}

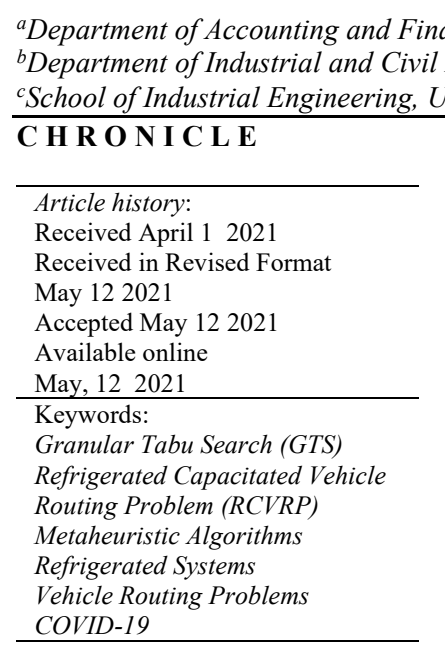

(C) 2022 by the authors; licensee Growing Science, Canada

\section{Introduction}

The globalization of the markets has forced companies to be more efficient and productive in their distribution and operation processes. Reducing logistics costs in distribution and transportation operations has been a topic covered by a large amount of research since the mid-20th century. One of the well-known problems is the classic Capacitated Vehicle Routing Problem (CVRP). The main concern is determining the routes while minimizing the route costs associated with the distance. The CVRP is formally defined by considering a complete undirected graph $G=(V, E)$, where $V=\{0, \ldots, n\}$ is the set of vertices. $V_{i}$ with $i=\{1, \ldots, n\}$ represents a customer that has a nonnegative demand $q_{i}$, while the vertex $V_{i}=0$ represents the depot. Each arc $e \in E=\{(i, j): i, j \in V, i \neq j\}$ is associated with a cost per trip $c_{i j}$, where $i$ and $j$ represent the origin and destination vertices, respectively. A set $M$ of available vehicles with the same characteristics (homogeneous fleet) is defined with capacity $Q$ per vehicle (Bernal et al., 2018). Eksioglu et al. (2009) propose a methodology for classifying the Vehicle Routing Problem (VRP) literature. This paper defines VRP's domain in its entirety, accomplishes an all-encompassing taxonomy for the VRP literature, and delineates all of VRP's facets in a parsimonious and discriminating manner. Moreover, all previously published VRP taxonomies are shown to be relatively myopic. There is a constant evolution in the quality of the VRP's methodologies. According to Villagra et al. (2011), some of the solutions use heuristics and metaheuristics. For example, Tabu Search (Cordeau et al., 1997; Xia \& Fu, 2019; Prajapati et al., 2020; Bernal et al., 2017) Simulated Annealing (Osman 1993, Karagul et al., 2019; Aydemir \& Karagul, 2020), Ant Colony (Bell \& McMullen, 2004; Li et al., 2019), and Evolutionary Algorithms (Baker \& Ayechew, 2003; Xu et al., 2015) have been proposed. The CVRP has become an essential focus of attention by the transportation industry since one of the significant challenges is to guarantee a correct distribution process with a limited number of resources. Likewise, the transportation industry has sectors presenting constraints and challenges, making the distribution process more expensive, such as the refrigerated product transportation sector. In this sector, it is essential to

* Corresponding author

E-mail: john.wilmer.escobar@,correounivalle.edu.co (J. W. Escobar)

2022 Growing Science Ltd. doi: $10.5267 /$ j.ijiec.2021.6.001 
consider and evaluate the influence of additional variables on the process since these could affect transportation costs (James et al., 2009). The refrigerated product transportation sector focuses on distributing products requiring temperature control throughout their distribution routes. These transport conditions generally apply to the food and pharmaceutical industries (meat, dairy, fruit, COVID-19 vaccines). During the distribution process, the temperature of these products is an essential factor due to them being under strict conditions and in good shape at their final destination. During the transport process, the aim is to preserve the vehicle's temperature, thereby reducing its variability. Different factors along the route could influence the temperature. Some examples of the factors affecting thermal conditions are the climate of the external environment, internal conditions of the load, insulation properties of the truck container, filtration of hot air, exposure time with the air from the external environment, relative humidity of the cargo, and quantity of refrigerated products inside the vehicle, among others (Novaes et al., 2015). For the transport of products with a refrigerated fleet, the energy consumption dedicated to cooling varies depending on various factors influenced by day. Each variable changes over time, generating a higher or lower energy consumption depending on the weather conditions. The main goal is to find the routes for refrigerated vehicles' fleets, minimizing the costs of maintaining stable thermal conditions inside the vehicles to avoid cost overruns from the refrigeration system. This problem has been called the Refrigerated Capacitated Vehicle Routing Problem (RCVRP).

The work performed by the cooling system during certain stages of the route leads to increase energy consumption. This situation generates a reduction in the cooling system's energy consumption, implying an impact on transportation costs for fuel consumption. Therefore, considering the influence of the environment on the refrigeration system's behavior can lead to routing decisions affecting transportation costs in fuel per kilometer traveled, as is performed in non-refrigerated vehicle consumption. There are external and internal factors affecting the temperature of the cargo inside the vehicle. Fig. 1 shows an example of the temperature behavior data during a refrigerated food distribution process. The described route consists of 8 delivery points. Fig. 1 shows as the temperature increases along the route. In the early stages of the route, the temperature shows low variability, increasing the nodes' visits between 160 and 250 minutes. Additionally, it is evidenced that the temperature changes when the route is performed, showing significant changes after minute 360 . From Fig. 1 , we conclude that the temperature could vary when the stops increase along the route. Indeed, it is possible to identify the moments in which the refrigeration system must perform more work to adjust the temperature levels.

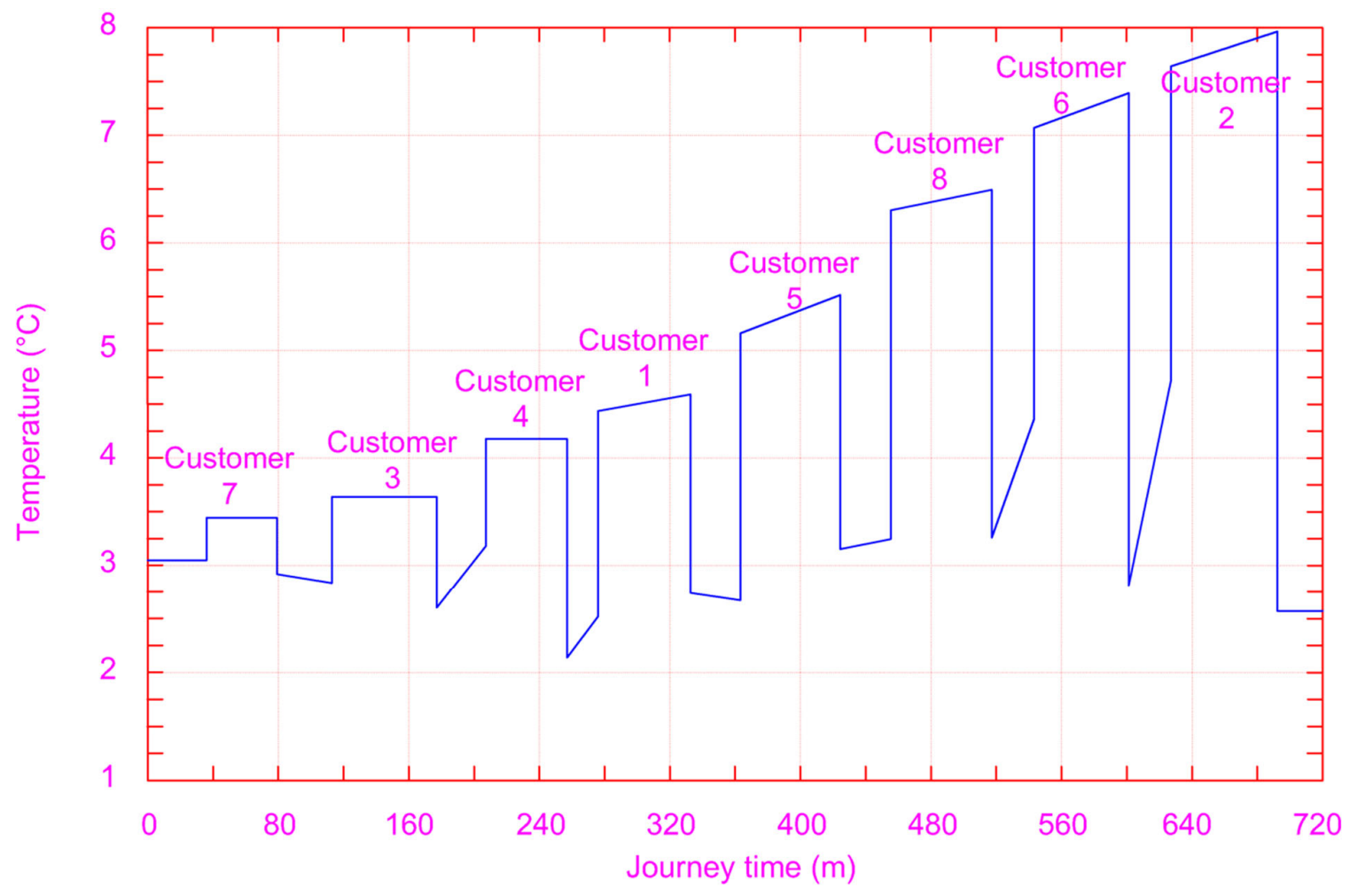

Fig.1. Temperature changes with respect to the performed route (Adapted of Novaes et al., 2015)

The truck's stored mass decreases as deliveries are performed, allowing more warm air to flow into the truck. This situation causes the refrigeration system to require more work to maintain the cold chain. In this case, the need to include thermal considerations in the vehicle routing problem for refrigerated products is highlighted since energy consumption is included in the route's total cost. 
It is essential to know and identify the different thermal phenomena during the vehicle's route that affect the truck's internal temperature and generate higher energy consumption. It is also necessary to identify the vehicle's cooling system's technology to know the cooling mechanism and relevant energy consumption points. In the CVRP problem, routing decisions are based on savings in terms of distances between nodes. However, for the CVRP problem considering a homogeneous and refrigerated fleet, it is essential to take into account the consideration of routing decisions not only in terms of distance but also concerning other aspects, such as the influence of air infiltration from outside and the influence of heat from the outside environment on the internal load of the trucks (Fourier's law). The proposed algorithm's main body is divided into two sections: (I) constructing an initial solution using a hybrid method and (II) a granular tabu search scheme to refine the initial solution obtained in (I). The former algorithm considers modern methods for determining the route's thermal conditions for the RCVRP. However, according to the literature examined, no efforts have been made to integrate any of these elements, allowing for a more precise supply decision-making method for routing problem design.

The following is a breakdown of the paper's structure. Section 2 is devoted to a comprehensive study of the literature. The proposed algorithm is defined in Section 3 of the paper. In Section 4, the experimental findings on benchmark instances from the literature are presented. Finally, section 5 concludes with findings and recommendations for future studies.

\section{Review of Literature}

The refrigerated product transport sector has great importance in recent years, especially in the COVID-19 pandemic. Indeed, it must be ensured that products (such as vaccines) are kept in optimal conditions during transport. Furthermore, reducing customs costs and free trade agreements has increased refrigerated products' commercialization between countries, implying a huge challenge for logistics operators since doing so necessarily requires efficient distribution and maintenance of the products' quality. Therefore, the challenge is to guarantee that the products reach customers in their optimal condition while ensuring that transportation cost is minimal. The transportation of refrigerated products is closely related to the well-known Capacitated Vehicle Routing Problem (CVRP). In this case, the transportation costs depend on the routing based on distance, while the inventory costs are calculated according to the product's deterioration due to its transportation process. In addition, extra costs are incurred for refrigeration equipment's energy consumption to preserve the products during routing. Hsu \& Hung (2003) propose a model for the vehicle routing problem applied to refrigerated cargo transportation, minimizing transportation, inventory, and energy costs. In Novaes et al. (2015), transporting refrigerated products focuses on ensuring that the products' temperature is preserved during the distribution process, minimizing its variability. In this case, the development of an algorithm based on simulated annealing is described to calculate the minimum distance of travel, considering the quality indicators based on the temperature variability along the route. Tarantilis and Kiranoudis (2001) propose a fast and robust algorithm for solving the fresh-milk distribution problem. The problem has been formulated as a heterogeneous fixed-fleet vehicle routing problem (HFFVRP). A threshold-accepting-based algorithm has been developed to repeatedly satisfy the company's need to use this methodology repeatedly to schedule their distribution many times a week. Zhang et al. (2003) presented a tabu search algorithm to optimize cold chain structures to distribute chilled or frozen foods. The physical distribution system is structured to minimize storage and transportation costs in the whole distribution while the product quality requirement is fulfilled. Hsu et al. (2007) present the vehicle routing problem with time windows (VRPTW) by considering the perishable food delivery process's randomness. The objective is to minimize the fixed costs for dispatching vehicles and the transportation, inventory, energy, and penalty costs for violating time windows. Kara et al. (2007) propose a new cost function based on the vehicle's distance and load for the CVRP. The vehicle-routing problem with this new loadbased cost objective is called the Energy Minimizing Vehicle Routing Problem (EMVRP). Integer linear programming formulations with $\mathrm{O}(\mathrm{n} 2)$ binary variables and $\mathrm{O}(\mathrm{n} 2)$ constraints are developed separately for the collection and delivery cases. Osvald and Stirn (2008) propose an algorithm for distributing fresh vegetables where perishability represents a critical factor. This particular problem has been formulated as a Vehicle Routing Problem with Time Windows and Time-Dependent travel times (VRPTWTD). The model considers perishability as part of the overall distribution costs, and a heuristic approach based on the tabu search is used to solve the problem. Tassou et al. (2009) provide a review of (a) current approaches for road food transport refrigeration, (b) estimates of their environmental impacts, and (c) research on the development and application of alternative technologies to vapor compression refrigeration systems having the potential to reduce the overall energy consumption and environmental impacts. Tassou et al. (2010) mention that refrigeration has become an essential part of the food chain. In the refrigeration process, mechanical technologies are invariably employed, contributing significantly to the food sector's environmental impacts through direct and indirect greenhouse gas emissions. Zanoni et al. (2012) study the differences between FSCs (short vs. longer product lives and storage times, fast vs. slower transportation, low vs. higher energy contribution), capturing the relationships between the relevant parameters influencing the problem. Zhang and Chen (2014) address a vehicle scheduling problem encountered in the frozen food delivery industry's cold chain logistics. An optimization model that manages the delivery of a variety of products has been proposed. The delivery cost includes the transportation cost, refrigeration cost, penalty cost, and cargo damage cost based on different frozen food product characteristics. Wu et al. (2013) present a model for assessing the carbon footprint of food transport refrigeration systems. The model was used to evaluate the carbon footprint of food transport refrigeration systems with three refrigerants. High ambient temperatures and lower refrigeration temperatures lead to more $\mathrm{CO} 2$ emissions. In addition, refrigerators driven by auxiliary engines have higher $\mathrm{CO} 2$ emissions than refrigeration systems driven by the main vehicle engine or electricity. Li (2017) presents comprehensive investigations of the total lifetime CO2-equivalent emissions for food transport refrigeration 
systems under various influencing factors. In addition, the new R404A alternative refrigerant, R452A, is investigated to provide improved environmental performance.

Song and Ko (2016) consider a vehicle routing problem encompassing refrigerated and general-type vehicles for multicommodity perishable food product delivery. The capacity, maximum delivery time, and the available number of refrigerated and general-type vehicles are predetermined. A nonlinear mathematical model and a heuristic algorithm to generate efficient vehicle routings to maximize the total level of customer satisfaction are proposed. Wang et al. (2017) consider optimizing the vehicle routing problem (VRP) with time windows for cold chain logistics based on China's carbon tax. Rai and Tassou (2007) consider using liquid carbon dioxide and liquid nitrogen-based cryogenic refrigeration systems for temperature-controlled food transport applications and provide a comparative assessment of these systems with conventional vapor compression systems driven by an auxiliary diesel engine. Two refrigerated vehicles (one rigid and one articulated), two food products (one chilled and one frozen), and three delivery schedules (long multidrop delivery, continuous multidrop delivery, and fast delivery) are used for assessment purposes. A cold chain vehicle routing problem with fuzzy time windows (CVRPFTW) was proposed by Tang and Huang (2018). The two-stage algorithm, CVRPFTW, is decomposed into two subproblems: a traditional vehicle routing problem with time windows for cold chain and a service improvement problem. Each of the objectives is sequentially solved. Finally, experiments based on a real fresh food company are conducted, and the results show that the CVRPFTW model can achieve considerable cost savings while at the same time maintaining an acceptable customer satisfaction level. Meneghetti et al. (2018) introduce refrigeration loads considering fuel consumption for palletized frozen food deliveries from a central refrigerated warehouse. In particular, infiltration loads during unloading operations are evaluated, and transmission loads both during traveling and at stops for customers, taking into account changes in outdoor temperatures. A minimum fuel consumption multiperiod optimization model has been developed and solved by constraint programming and then applied to supermarkets' local networks. Chen et al. (2019) studied the vehicle routing problem from a real cold chain distribution. This problem is formulated as a multicompartment vehicle routing problem with some practical constraints. A mathematical model is provided, and an Adaptive Large Neighborhood Search (ALNS) algorithm is developed to solve real-world problems. Recently, Liu et al. (2020) proposed a joint distribution-green vehicle routing problem (JD-GVRP) model in which companies collaborate to deliver cold chain commodities by considering carbon tax policies. A simulated annealing (SA) algorithm is applied to solve the JD-GVRP. The results indicate that joint distribution is an effective way to reduce total costs and carbon emissions than the single distribution. Furthermore, the total cost is positively correlated with the carbon price, while the carbon emissions vary differently when the carbon price increases. In addition, carbon quotas do not affect the delivery path.

The transportation of refrigerated food is becoming a crucial aspect of the chain, ensuring efficiency and sustainability while maintaining a high product quality level. The recently defined refrigerated routing problem (RRP) consists of finding the optimal delivery tour minimizing the fuel consumption for both the traction and refrigeration components (Ceschia et al., 2020). The total fuel consumption is related to the distance traveled, the vehicle load and speed, and the outdoor temperature. All these factors depend on the traffic and the region's climate conditions where deliveries occur during the day and the year. Meneghetti and Ceschia (2020) consider the refrigerated routing problem involving multidrop deliveries of palletized unit loads of frozen food from a central depot to customers. The problem formulation considers speed variation due to traffic congestion phenomena and the decreasing load on board along the route as successive customers are visited. The resulting multiperiod problem is modeled and solved using constraint programming. The results show how fuel minimization leads to selecting different routes than traditional total travel distance or time objectives. Finally, Zhao et al. (2020) considered optimizing the transportation routing problem with time windows for fresh food in a time-varying road network by considering both economic cost and fresh food safety loss. A calculation method for the path division strategy is designed. A metric function of energy and heat conversion, a measure function of the carbon emission rate, is employed by considering timevarying vehicle speeds, fuel consumption, cost of temperature control, loss of food safety reliability, and carbon emissions from transportation and temperature control.

\section{Proposed Methodology}

\subsection{Thermal considerations of the problem}

In the proposed algorithm, we have considered a vehicle that produces the necessary cold through a thermodynamic refrigeration cycle by vapor compression. The system considers a compressor, an evaporator, a condenser, and an expansion valve. These elements work together to extract the heat produced inside the refrigerated tank and reject it to the environment through hot air, thus needing to supply power to the compressor (Fig. 2). Some factors that affect the energy performance of the refrigerated vehicle are the vehicle's van exposure to direct thermal radiation and high ambient temperatures (which vary depending on the time of day and weather phenomena), the relative humidity of the environment, the vehicle's travel speed, the duration of the routes, and the loading and unloading time of merchandise, among others. It is necessary to calculate two different thermal loads: the first caused by the transmission of heat on the walls, ceiling, and floor and the second by air infiltration through the door access to the refrigerated tank to quantify the energy performance of refrigerated vehicles. In the 
transmission through walls, the given load is presented in terms of heat transfer in the space cooled by its surface, and for infiltration, it is the heat gain associated with the air entering the cooled space.

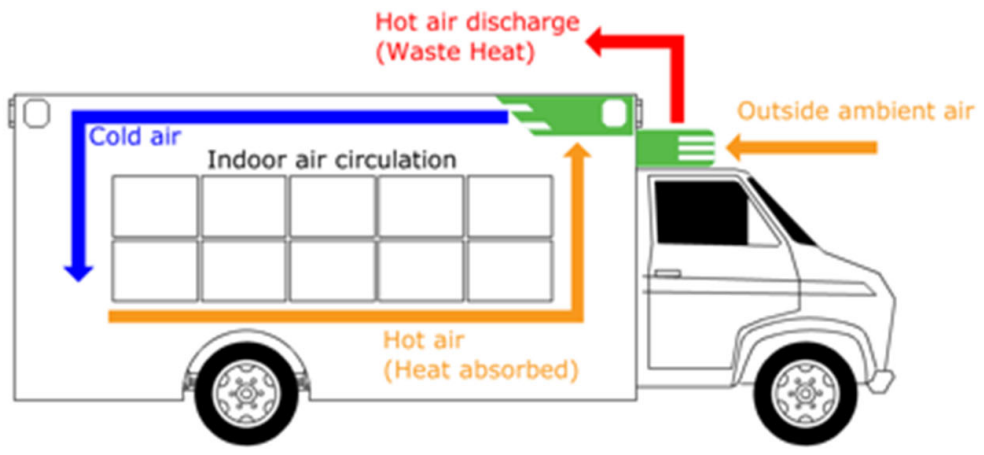

Fig. 2. Air flow into the vehicle (Source: Owner)

Calculating the aforementioned thermal loads, the amount of thermal energy per unit of time that must be removed from the refrigerated tank is instantly found, as is information on energy and fuel consumption that the truck must dedicate to the cold to maintain safety products transported. Fourier's law approximates the amount of heat $(Q)$ flowing inward due to constant exposure to the sun throughout the day at a given time $t$. It should be noted that Fourier's law considers constants such as the thermal conductivity of the material and the dimensions of the van for the calculation of the cross-sectional area (Prosen \& Robnik, 1992). In (1), the Fourier equation in a steady-state incorporated into the proposed algorithm is shown:

$$
Q=k \times A \frac{T_{\text {outside }}-T_{\text {inside }}}{\Delta Z}
$$

where:

$k$ $=$ constant of proportionality (thermal conductivity) in $\mathrm{J} / \mathrm{K} * \mathrm{~cm}$

$A$ $=$ cross-sectional area (for the problem under consideration, this represents the area of the walls of the truck)

$T_{\text {outside }}=$ outside temperature

$T_{\text {inside }} \quad=$ inside temperature

$\Delta Z \quad$ = change in the thickness of the truck wall

\subsubsection{Thermal load calculation by transmission}

This load refers to the sensible heat gain for walls, floors, and ceilings. The ASHRAE (2017) methodology was followed to calculate these loads. This gained heat calculated in the steady-state is formulated by expression (2):

$$
q=U A \Delta t
$$

where

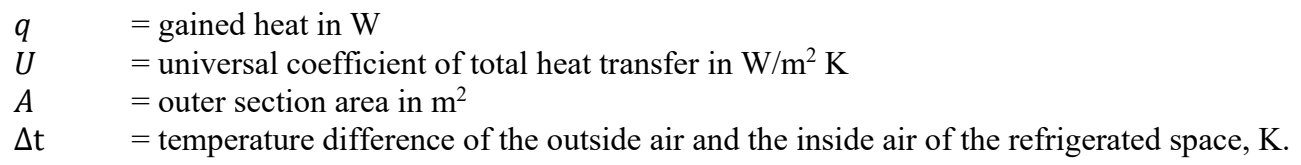

The universal coefficient of total heat transfer $(U)$ of the wall is calculated by (3):

$$
U=\frac{1}{\frac{1}{h_{i}}+\frac{x}{k}+\frac{1}{h_{0}}}
$$


where

$x \quad=$ wall thickness in $\mathrm{m}$

$k=$ thermal conductivity of wall heat in $\mathrm{W} / \mathrm{m} \mathrm{K}$

$h_{i} \quad=$ internal surface thermal conductance in $\mathrm{W} / \mathrm{m}^{2} \mathrm{~K}$

$h_{0} \quad=$ external surface thermal conductance in $\mathrm{W} / \mathrm{m}^{2} \mathrm{~K}$

\subsubsection{Thermal load calculation by infiltration}

This thermal load refers to the amount of gained heat by the infiltration of the outside air into the refrigerated space. In this case, the thermal load by infiltration occurs when the doors are opened to introduce the trout baskets. The expression (4) follows:

$$
q_{t}=q D_{t} D_{f}(1-E)
$$

where

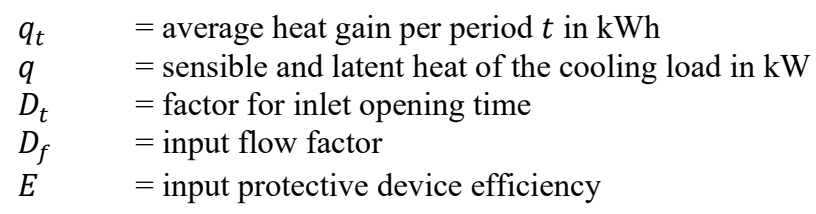

To obtain the variable $q$, the execution of expression (5) is used:

$$
q=0,577 W H^{1,5}\left(\mathrm{Q}_{s} / \mathrm{A}\right)\left(1 / \mathrm{R}_{s}\right)
$$

where

$\mathrm{Q}_{s} / \mathrm{A}=$ sensible heat of the infiltrated air load per square meter of open inlet in $\mathrm{KW} / \mathrm{m}^{2}$

$W \quad=$ input thickness in $\mathrm{m}$

$\mathrm{R}_{s} \quad=$ sensible heat gain ratio of air infiltration

To obtain the $\mathrm{Q}_{s} / \mathrm{A}$ values, we have used the obtained values of ASHRAE (2017).

For the factor calculation by the opening time of the input $D_{t}$, the times shown in Table 4 in the development section of the proposal are used. This calculation is made using expression (6):

$$
D_{t}=\left(P \theta_{p}+60 \theta_{o}\right) / 3600 \theta_{d}
$$

where

$$
\begin{array}{ll}
P & =\text { number of entrance corridors } \\
\theta_{p} & =\text { time to open and close the door } \\
\theta_{o} & =\text { door stay-open time, min } \\
\theta_{d} & =\text { daily (or other) time period, } \mathrm{h}
\end{array}
$$

\subsubsection{Model for calculating fuel consumption}

The thermal load calculation requires knowing the produced heat inside the vehicle to determine the energy consumption of the compressor and, later, the fuel consumption associated with the refrigeration process. First, it is necessary to know the coefficient of operation of the refrigeration system $(C O P)$, which is defined as follows:

$$
C O P=Q / W
$$

where 
$Q \quad=$ heat absorbed by the cooling system inside the vehicle in $\mathrm{kW}$

$W \quad=$ power consumed by the compressor in $\mathrm{kW}$

It is necessary to consider the value of $C O P$ when calculating fuel consumption. For this reason, a search was performed among the diesel-operated refrigeration systems commonly used by vehicles for the transport of refrigerated cargo. Once the $C O P$ value was obtained, equations (2) and (4) were used to calculate the heat by air infiltration. First, the total heat $Q$ removed by the cooling system was replaced. Then, with these two values and equation (2), the network necessary to maintain the controlled temperature is calculated. Then, equation (4) and the refrigeration system's efficiency were used to calculate the total work performed by the refrigeration system, taking into account that, for this case, it is not convenient to assume an ideal model where there is no loss of energy. According to Yumrutaş et al. (2002), the engines of a refrigeration system that works using a compression steam cycle suffer energy losses during the thermal cycle. Therefore, not all the work performed by the engine is used.

$$
W_{T}=\frac{W}{\text { Efficiency }}
$$

where

$$
\begin{array}{ll}
W_{T} & =\text { actual work done by the cooling system measured in } \mathrm{J} \\
W & =\text { work done by the cooling system measured in } \mathrm{J} \\
\text { Efficiency } & \text { = energy efficiency of the cooling system }
\end{array}
$$

Once the real work is obtained, the value of $W_{T}$ is taken, and its equivalent in fuel consumption is calculated. Finally, the equivalent in gallons of fuel is calculated using the following expression to carry out this calculation.

$$
\text { Ecost }=n g a l=\frac{W_{T}}{P C}
$$

where

$P C \quad=$ joules per gallon equivalent for diesel in $\mathrm{J} / \mathrm{gal}$

\subsection{Granular search algorithm}

The proposed granular tabu search algorithm consists of two parts: 1) an initial solution adapted from Bernal et al. (2018) and 2) a granular tabu search approach. The two procedures are described in detail in the following pages.

\subsubsection{Initial Solution}

Bernal et al. (2018) suggested a hybrid heuristic based on an updated Clark and Wright protocol to generate the initial solution $S_{o}$ for the well-known CVRP. Different from Bernal et al. (2018), we have adapted this heuristic method by considering saving fuel consumption instead of saving distance. The first solution uses the following function to measure the value of fuel consumption savings between a pair of customers $(i, j)$ :

$$
S_{i j}=\frac{e_{i 0}+e_{0 j}-\lambda e_{i j}}{E_{\max }}+\mu \cos \left(\theta_{i j}\right) \frac{\left|E_{\max }-\left(e_{i 0}-e_{0 j}\right) / 2\right|}{E_{\max }}+v \frac{\left|\bar{d}-\left(d_{i}+d_{j}\right) / 2\right|}{d_{\max }}
$$

where $e_{i j}$ is the fuel consumption between a pair of nodes $i$ and $j$ ( 0 is the depot node), $E_{\text {max }}$ is the overall fuel consumption between two nodes of the complete graph calculated by (9), $\theta_{i j}$ is the angle between the two rays extending from the depot to nodes $i$ and $j, d_{i}$ is the demand of node $i, \bar{d}$ is the average demand, and $d_{\text {max }}$ is the maximum demand of a node of the complete graph. $\lambda, \mu$ and $v$ are given parameters whose values change depending on the conditions of each collection of benchmarks. The initial solution's pseudocode is shown in Algorithm 1.

Algorithm 1. Heuristic algorithm adapted from Bernal et al., (2018)

Procedure FCS (customers, fuel consumption, vehicles)

Calculate fuel saving list by (10)

Order fuel saving list decreasing 
For each saving in saving_list do

Evaluate demand, total route length and service time if saving is applied

If all constraints are fulfilled then

Apply saving

Calculate demand, total fuel consumption of route and service time

Else

Ignore saving

End

\subsubsection{Granular search space}

The proposed algorithm uses the idea of granular tabu search (GTS) introduced by Toth and Vigo (2003) for the CVRP. GTS's goal is to significantly reduce the computing time during search compared to a conventional tabu search. According to Toth and Vigo (2003), the idea of granular search is the use of a candidate list containing reasonable solutions belonging to a neighborhood. In our case, the granular search space is made up of the list of candidates obtained by the union of "arcs with lower fuel consumption", arcs incident to the depots, and arcs belonging to the best solutions found thus far during the search process. An "arc with lower fuel consumption" is defined as an arc whose fuel consumption value is less than the granularity value $(v)$ calculated in Eq. (11). As mentioned above, the purpose of the granular search is that a candidate's use reduces the number of unpromising movements within the search space. The best movements depend on a dispersion parameter called $\beta$ (Toth \& Vigo, 2003).

$$
v=\beta \times \frac{z^{\prime}}{(n+k)}
$$

where $\beta$ is a positive sparsification factor, $z^{\prime}$ is the objective function of the initial solution (fuel consumption of routes belonging $S_{0}$ ), $n$ is the number of customers, and $k$ is the number of routes belonging to the initial solution. According to Escobar et al. (2013), Escobar et al. (2014a) and Escobar et al. (2014b), a change in the value of $\beta$ allows the algorithm to switch between intensification stages (high values of $\beta$, called $\beta_{I}$ ) and diversification stages (small values of $\beta$, called $\beta_{D}$ ). The granular tabu search's main goal is to find high-quality solutions by keeping the main characteristics of the original tabu search within short computing times (Escobar \& Linfati, 2012). Successful algorithms based on the idea of granularity for solving different variations of the vehicle routing problem have been proposed by Linfati et al. (2014) and Puenayán et al. (2014).

\subsubsection{Neighborhood structures}

Only feasible solutions in terms of vehicle capacity and duration of the routes are allowed under the former algorithm. A feasible solution $S$ is composed of a set of $z$ routes $\left(r_{1}, \ldots, r_{z}\right)$ with each route $r_{l}$, where $l \in\{1, \ldots, z\}$, is denoted by $\left(v_{0}, v_{1}, v_{2}, \ldots, v_{0}\right)$, and $v_{0}$ is the depot node. We assign to $S$ an objective function value $F_{1}(S)=\sum_{l=1}^{z} E \operatorname{cost}_{l}$, where $E \operatorname{cost}_{l}$ is the fuel consumption for each route $z$.

The proposed algorithm uses intra-route and inter-route moves corresponding to the following neighborhoods:

- Insertion: A customer is moved from its present position to a new position on the same route or to a different route altogether.

- Swap: Two customers (in the same route or different routes) exchange their position.

- Double insertion: By holding the edge linking two consecutive customers, they are separated from their current location and placed into the same or a separate route.

- Double swap: By considering two consecutive costumers, this move is an expansion of the Swap move. The edge connecting each customer pair is hold. The transfer is carried out in two separate routes for pairs of customers.

- Two-opt: We use the well-known 2-opt move used for the CVRP (intra-route and inter-route moves).

If the new edges to be added in the current solution belong to the granular search space, the move is performed. Finally, we apply a shaking method that expands the concept of the insertion move by considering three random routes at the same time whenever the proposed algorithm remains in a local minimum for $N_{\text {shake }}$ iterations (where $N_{\text {shake }}$ is a given parameter). For further details, see (Escobar et al., 2014a; Escobar et al., 2014b). 


\subsubsection{Perturbation procedure}

The proposed approach is based on Bernal et al. (2018) by selecting three routes. The first route $(k 1)$ is selected randomly. The second route $(k 2)$ is the nearest neighborhood of route $k 1$, and route $(k 3)$ is the nearest neighborhood of $(k 2)$. The fuel consumption of routes is calculated by considering their center of gravity. Then, the procedure randomly selects customer $i 1$ from route $k 1$, customer $i 2$ from route $k 2$, an edge $(h 2, j 2)$ from route $k 2$ (with $h 2 \neq i 2$ and $j 2 \neq i 2)$, and an edge ( $h 3$, $j 3$ ) from route $k 3$. Therefore, the new solution $S$ is obtained by considering the following moves: 1) remove customer $i 1$ from route $k 1$, and insert it between vertices $h 2$ and $j 2$ in route $k 2$; and 2) remove customer $i 2$ from route $k 2$, and insert it between vertices $h 3$ and $j 3$ in route $k 3$. The perturbation procedure allows exploration of new regions of the search space.

\subsubsection{Thermal Considerations}

A procedure has been implemented to include thermal considerations associated with transferring heat from the external environment to the load's interior. Therefore, it is possible to relate the temperature throughout the day and the amount of heat transferred per minute. The procedure (Fourier law) calculates the amount of heat transferred, taking into account the cargo's internal temperature and the dimensions and characteristics of the truck's material. We have defined a procedure for air infiltration as the amount of heat that the vehicle gains during the truck doors' opening when visiting a node during the route. It is necessary to calculate the percentage of the vehicle's vacuum, which varies depending on the visited node, to calculate the heat transfer by air infiltration. This percentage is multiplied by the truck's total volume to obtain the volume of space where the airflow from outside can circulate when the doors are opened (product discharge). Finally, the calculation of the energy cost considers the procedure when a movement is carried out. For this procedure, it is necessary to recalculate the modified route's energy consumption considering that heat transfer from the outside to the inside varies by the climate's state and impacts heat transfer occurring by air infiltration. Algorithm 2 shows EC for calculating the energy cost for each section of a route (segment between two consecutive nodes of a route) to obtain the total energy cost for a set of routes. This procedure considers aspects such as the calculation of the Fourier law and air infiltration. Additionally, we consider the departure time, environmental temperature, infiltration heat, and the amount of heat transferred from the outside environment to the inside of the truck.

Algorithm 2. Energy Cost Procedure

Procedure EC (truck length, truck height, truck width, routes, truck sheet thickness, distance, speed, service time, density air, heat air, external environmental temperature, internal environmental temperature, thermal conductivity constant, internal temperature truck, node)

Calculate truck surface area

Calculate volume truck

Calculate percentage empty truck

Calculate heat flow by (1)

acum time $\leftarrow 0$

Stime $\leftarrow 0$

For each route in routes do

Calculate Ttime

If node is depot then

Stime $\leftarrow$ Stime

Atime $\leftarrow$ Atime + Ttime

Else

Stime $\leftarrow$ Stime + Ttime

Atime $\leftarrow$ Atime + Ttime

Calculate air infiltration by (4)

Calculate Ecost by (9)

End for

End 
The energy cost calculation on the route includes the sequence of routes and the distance between each route's nodes. In particular, it is important to know the time and hour where the vehicle is exposed to the environment's heat. The starting time (Stime) corresponds to when the vehicle leaves the node in which it is located, and the travel time (Ttime) corresponds to the time taken from the previous node to the current node at an average speed. The total energy cost (Ecost) includes air infiltration and the heat transfer model from the environment to the vehicle's interior. The proposed approach, after the construction of an initial solution $S_{o}$ (by the procedure described in Section 3.4.1), iterates through different neighborhood structures to improve the best feasible solution $\left(S^{*}\right)$ found thus far, until a stopping criterion is reached (number of iterations or computing time). The algorithm starts by setting $S^{*}=\bar{S}=S_{0}$, where $\bar{S}$ is the current feasible solution. The following steps are then repeated until a stopping criterion (IT $\max$ iterations) is reached:

1. Select a neighborhood from the neighborhood structures $N_{k}(k=1, \ldots, 5)$ described in Section 3.4.3

2. Apply a Granular Tabu Search (GTS) in the selected neighborhood $N_{k}(\bar{S})$ until a local minimum $S^{\prime}$ is found;

3. If $S^{\prime}$ is feasible and $F_{1}\left(S^{\prime}\right) \leq F_{1}(\hat{S})$, set $\bar{S}:=S^{\prime}:=S^{*}$

Finally, Algorithm 3 presents the pseudocode of the general procedure of the proposed algorithm.

Algorithm 3. Granular Tabu Search Algorithm

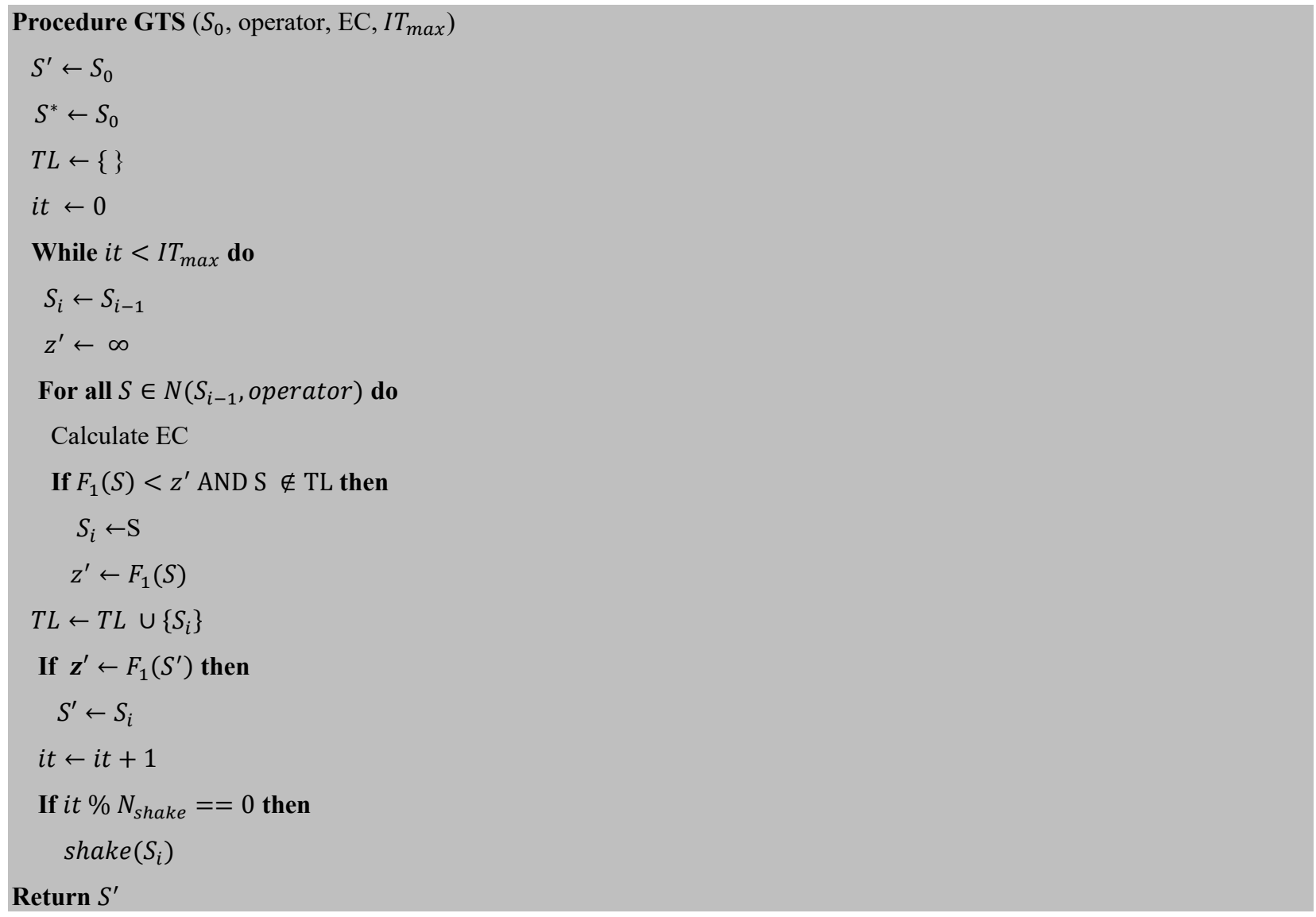

\section{Computational Results}

\subsection{Incidence of energy consumption}

A small example of a vehicle that carries refrigerated cargo is performed to validate the importance of energy consumption on refrigerated vehicle routes. The vehicle must visit five customers starting from the depot. In particular, the percentage of the truck's vacuum increasing when the product is dispatched, the arrival time to each customer, and the environmental temperature along the route are analyzed. In addition, the amount of heat flow considers the airflow when the doors are opened delivering products to each customer and the airflow due to the environment's influence. Finally, both heat flows are measured based on the vehicle's cooling system's work to maintain the truck's internal temperature. Table 1 shows the data collected for the $0-3-9-15-6-12-0$ route. 
Table 1

Information of the route $0-3-9-15-6-12-0$

\begin{tabular}{|c|c|c|c|c|c|c|c|c|}
\hline Node & $\begin{array}{l}\text { Coord X } \\
(\mathrm{km})\end{array}$ & $\begin{array}{l}\text { Coord } \\
\mathrm{Y}(\mathrm{km})\end{array}$ & $\begin{array}{l}\text { Load respect to } \\
\text { the capacity } \\
(\%)\end{array}$ & $\begin{array}{c}\text { Percentage } \\
\text { empty per } \\
\text { delivery to } \\
\text { customer }(\%)\end{array}$ & Hour & $\begin{array}{c}\text { Environmental } \\
\text { temperature }\left(C^{0}\right)\end{array}$ & $\begin{array}{c}\text { W Heat Transfer } \\
\text { KJ } \\
\text { (Fourier Law) }\end{array}$ & $\begin{array}{l}\text { W Heat Transfer KJ } \\
\text { (Air Infiltration) }\end{array}$ \\
\hline 0 & 0 & 0 & 10.24 & 10.24 & $6: 00$ & 22 & & 38.93 \\
\hline 3 & 4 & 10 & 17.69 & 27.93 & $8: 00$ & 22 & 299.74 & 101.95 \\
\hline 9 & 8 & -8 & 35.42 & 63.35 & $10: 00$ & 26 & 513.16 & 280.48 \\
\hline 15 & -8 & 4 & 3.22 & 66.57 & $12: 00$ & 27 & 673.77 & 304.38 \\
\hline 6 & -6 & 8 & 22.00 & 88.57 & $14: 00$ & 27 & 157.21 & 414.43 \\
\hline 12 & 4 & 14 & 11.43 & 100.00 & $18: 00$ & 23 & 409.96 & 366.82 \\
\hline \multirow[t]{2}{*}{0} & 0 & 0 & 0.00 & 100.00 & $20: 00$ & 20 & 426.53 & 311.80 \\
\hline & & & & & & Total & 2480.37 & $\mathbf{1 7 7 9 . 8 5}$ \\
\hline
\end{tabular}

Source: Owner

Table 2 shows the route's statistics after a swap move between nodes 9 and 12 in the route's sequence. The exchange of nodes generates a decrease in the work $(W)$ performed by the cooling system to maintain the truck's internal temperature.

Table 2

Information of the route $0-3-12-15-6-9-0$

\begin{tabular}{cccccrrr}
\hline Node & $\begin{array}{c}\text { Coord } \\
\mathrm{X}(\mathrm{km})\end{array}$ & $\begin{array}{c}\text { Coord } \\
\mathrm{Y}(\mathrm{km})\end{array}$ & $\begin{array}{c}\text { Load respect to } \\
\text { the capacity } \\
(\%)\end{array}$ & $\begin{array}{c}\text { Percentage } \\
\text { empty per } \\
\text { delivery to } \\
\text { customer }(\%)\end{array}$ & Hour & $\begin{array}{c}\text { Environmental } \\
\text { temperature }\left(C^{0}\right)\end{array}$ & $\begin{array}{c}\text { W Heat Transfer KJ } \\
(\text { Fourier Law) }\end{array}$ \\
\hline 0 & 0 & 0 & 10.24 & 10.24 & $6: 00$ & 22 & 22 \\
$($ Air Infiltration)
\end{tabular}

Source: Owner

The exchange of two nodes (9 and 12) within a route based on thermodynamic aspects impacts the cooling system. Therefore, this variation already represents an interest in developing an algorithm that solves a CVRP-type problem considering thermodynamic aspects for routing with a homogeneous and refrigerated fleet.

\subsection{Analysis of results}

The proposed algorithm has been coded in $\mathrm{C}++$, and computational experiments have been conducted on an Intel Core CPU $(2.30 \mathrm{GHz})$ under Linux Ubuntu 12.1 with $32 \mathrm{~GB}$ of memory RAM. The proposed algorithm's efficiency has been validated in the instances adapted CMT3, CMT6, CMT9, CMT10, Tai75a, Tai100c, M-n101-k10, M-n121-k7, X-n106-k14, and Xn110-k13 for the CVRP problem. In all the sets, points in the plane represent the customers and the depot. Therefore, the traveling cost for an edge is considered in kilometers. The characteristics of the instances, such as the number of nodes $(N)$, number of vehicles $(K)$, maximum capacity for each vehicle $(Q)$, and the best solution found in terms of distance, are presented in Table 3. Additionally, we have added some parameters related to the characteristics of the vehicles used, as shown in Table 4. We have defined independent parameters whose values must be determined by extensive computational experiments for the proposed approach. These parameters are considered candidate settings for any given factor. Since the performance of the proposed approach depends on the value for each of the above-described parameters, a calibration process has been carefully performed. This procedure is iteratively performed by considering every single factor (variable) and finds its "best value," giving the lower objective function. The initial values of some parameters (value of $\beta_{I}$ and $\beta_{D}$ ) are obtained from previous granular search works for some variants of routing problems (Escobar, 2013, Escobar et al., 2014a; Escobar et al., 2014b). The value of $\beta_{I}$ and $\beta_{D}$ are sensitive in the refinement phase due to if these values are high, more arcs are considered (i.e., more options to explore in the refinement process) but, at the same time, the computing time is increased. On the other hand, if the value for this parameter is low, the problem becomes more restrictive (i.e., less option to take into account while improving the routes). In this way, initial values of $\beta_{I}$ and $\beta_{D}$ have been considered from 0.5 to 2.5 with increases of 0.25 . According to Toth \& Vigo (2003), the quality of the solutions found for routing problems is not directly proportional to the increase of the sparsification parameter, which is associated with a more significant computational effort. We determine that the considered values of sparsification factors allow achieving between $10 \%$ and $20 \%$ of the arcs of the complete graphs obtaining high quality in a reduced computing time. The value of the sparsification parameters has been adjusted for all the complete sets of instances considering each operator's performance. In this way, a comparative analysis of the efficiency and quality of the solution was carried out. The other parameters were adjusted by implementing extensive computational tests, fixing the operator that generates the best quality solutions. We examine the parameters sequentially according to their a priori importance and attempt to find the "best" treatment for each factor based on the test results. (Note that the order in which factors are examined is essential since it may impact the total number of tests required for the tuning procedure). Indeed, we 
have first fixed the sparsification parameters, then the tabu tenure $(T L)$ and the value of $N_{\text {shake }}$ Finally, the number of iterations is set. In addition, for the initial solution procedure, we have adopted the values of parameters $\lambda=1, \mu=0$, and $v=1$ considered by Bernal et al. (2018). Table 4 shows the considered parameters of the granular tabu search procedure.

Table 3

Characteristic of Instances

\begin{tabular}{|c|c|c|c|}
\hline Instance & $\mathbf{N}$ & $\mathbf{K}$ & $\mathbf{Q}$ \\
\hline CMT3 & 100 & 8 & 200 \\
\hline CMT6 & 50 & 6 & 160 \\
\hline CMT9 & 150 & 14 & 200 \\
\hline CMT10 & 199 & 18 & 200 \\
\hline M-n101-k10 & 100 & 10 & 200 \\
\hline M-n121-k7 & 120 & 7 & 200 \\
\hline X-n106-k14 & 105 & 14 & 600 \\
\hline X-n110-k13 & 109 & 13 & 66 \\
\hline tai75a & 75 & 10 & 1445 \\
\hline tai100c & 100 & 11 & 2043 \\
\hline
\end{tabular}

Source: Owner

Table 4

Parameters

\begin{tabular}{|c|c|c|}
\hline \multicolumn{3}{|c|}{ Granular Tabu Search Parameters } \\
\hline \multicolumn{3}{|c|}{$\beta_{I}=1 \quad \beta_{D}=2 T_{\max }=600 \quad N_{\text {shake }}=30 \mathrm{TL}=7$} \\
\hline \multicolumn{3}{|c|}{ Characteristics of Vehicles } \\
\hline Variable & Description & Units \\
\hline Truck length & 6.5 & $\mathrm{~m}$ \\
\hline Truck height & 2.5 & $\mathrm{~m}$ \\
\hline Truck width & 2.45 & $\mathrm{~m}$ \\
\hline Truck sheet thickness & 0.05 & $\mathrm{~m}$ \\
\hline Truck engine & 146.7 & $\mathrm{cc}$ \\
\hline Speed & 14 & $\mathrm{~km} / \mathrm{h}$ \\
\hline Reference & V-400max & \\
\hline Technology & Vapor compression cooling system & \\
\hline Brand & Thermo King & \\
\hline $\mathrm{COP}$ & 2.24 & \\
\hline Calorific Power of Diesel & 138.362 .219 & $\mathrm{~W} / \mathrm{kg}$ \\
\hline Thermal Conductivity Constant (k) & 0.023 & $\mathrm{~W} / \mathrm{m}^{* \circ} \mathrm{C}$ \\
\hline Specific Heat of Air & 1.012 & $\mathrm{~J} / \mathrm{kg}^{* \circ} \mathrm{C}$ \\
\hline Motor Efficiency & 35 & $\%$ \\
\hline
\end{tabular}

Source: Owner

The proposed algorithm has been executed with the traditional CVRP function (Distance VRP) and the proposed thermal function (Thermal VRP). Table 5 summarizes the results in terms of a comparison of both algorithms. It is essential to mention that the Thermal VRP yields lower fuel consumption values and lower distances. Therefore, the problem could be considered a multiobjective vehicle routing problem.

Table 5

Comparison Thermal VRP and Distance VRP

\begin{tabular}{|c|c|c|c|c|c|c|}
\hline & The & I VRP & Dist & e VRP & & \\
\hline Instance & Distance(km) & $\begin{array}{c}\text { Fuel consumption } \\
\text { (gal) }\end{array}$ & Distance(km) & $\begin{array}{c}\text { Fuel consumption } \\
\text { (gal) }\end{array}$ & $\begin{array}{c}\text { Distance delta } \\
(\%)\end{array}$ & $\begin{array}{c}\text { Fuel } \\
\text { Consumption } \\
\text { delta }(\%)\end{array}$ \\
\hline CMT3 & 889.57 & 14.50 & 870.30 & 14.83 & 2.214 & -2.166 \\
\hline CMT6 & 584.86 & 9.38 & 562.93 & 9.75 & 3.896 & -3.750 \\
\hline СМТ9 & 1287.64 & 21.46 & 1287.64 & 21.46 & 0.000 & 0.000 \\
\hline CMT10 & 1434.07 & 23.81 & 1428.40 & 23.90 & 0.397 & -0.396 \\
\hline M-n101-k10 & 833.51 & 13.59 & 815.63 & 13.89 & 2.192 & -2.145 \\
\hline M-n121-k7 & 1071.07 & 17.53 & 1051.68 & 17.85 & 1.843 & -1.810 \\
\hline X-n106-k14 & 27275.77 & 45.17 & 27100.99 & 45.46 & 0.645 & -0.641 \\
\hline X-n110-k13 & 15386.57 & 25.64 & 15386.57 & 25.64 & 0.000 & 0.000 \\
\hline tai75a & 1645.50 & 27.15 & 1628.82 & 27.42 & 1.024 & -1.013 \\
\hline tai100c & 1586.50 & 25.82 & 1549.10 & 26.44 & 2.414 & -2.357 \\
\hline
\end{tabular}

Source: Owner 
Table 6 compares the best solution found in the literature, both for the Thermal VRP and Distance VRP. The GAP BKS was calculated in terms of distance for each algorithm.

Table 6

Comparison of Results respect to the BKS

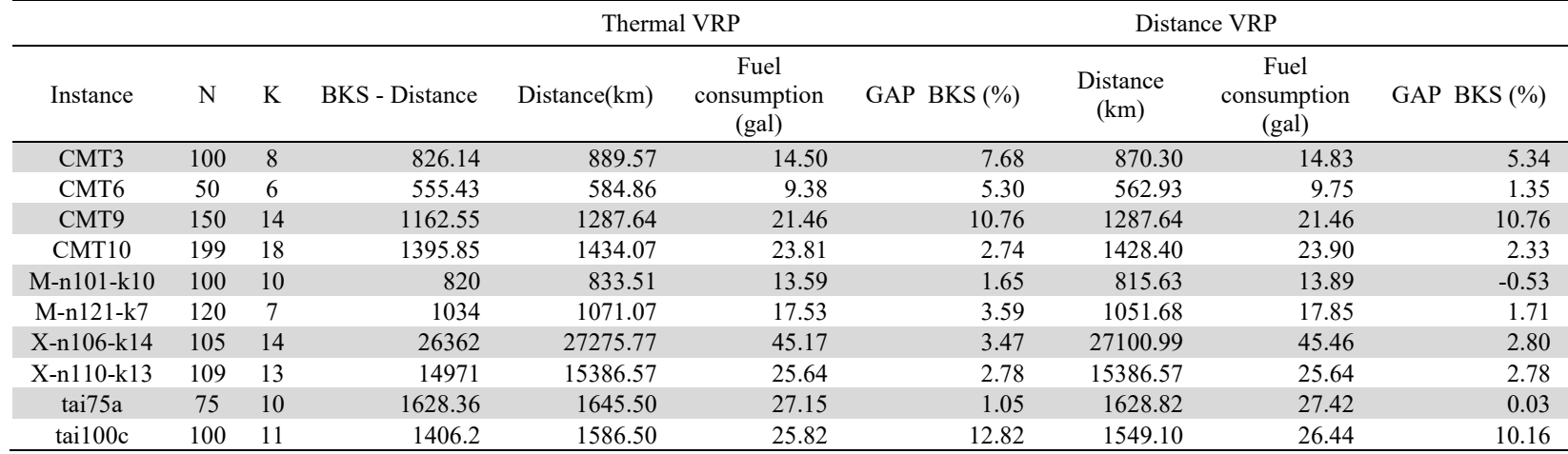

Source: Owner

From the results presented in Tables 5 and 6, the possibility of linking thermal aspects to a CVRP algorithm is identified since it generates changes in the routes. Therefore, we conclude that it is essential to analyze thermodynamic models to a VRP problem that could generate new solutions focusing on reducing costs concerning distance for the routes and involving aspects such as energy consumption costs.

\section{Concluding Remarks}

This paper proposes a granular tabu search approach for the Refrigerated Capacitated Vehicle Routing Problem (RCVRP). The algorithm is based on the granular tabu search introduced by Toth and Vigo (2003) for the well-known CVRP. Following the construction of an initial solution using a hybrid heuristic, we apply a granular tabu search procedure considering five neighborhoods, favoring the moves that have strengthened the best solution found thus far. When the algorithm stays in a local optimum after a certain number of iterations, a perturbation procedure is used. The proposed algorithm considers temperature along the route, travel times, fuel consumption, heat transfer, air infiltration, and cooling system characteristics. These variables allow the calculation of the energy cost for a route. In particular, although the diesel fuel consumption for the refrigeration equipment is linked to the travel time, involving the distance and speed of the vehicle, there are cases in which the result of the Thermal VRP achieves more significant fuel savings compared to the result of the Distance VRP. It is essential to mention that a minimum distance route does not imply that the cooling system's fuel consumption is minimal. When the vehicle is exposed to daily temperatures, it is crucial to consider energy savings for cooling products. However, it is not a definitive factor when choosing a route in which it is considered to minimize the impact of environmental temperature on energy consumption to maintain a continuous temperature inside the vehicle.

Future works are recommended to include the environmental impact of energy consumption by the cooling system. Similarly, the problem could be extended by considering dependent time routes and exploring multiobjective considerations (Bolaños et al., 2015; Chávez et al., 2016). Similarly, other solution techniques could be explored using population metaheuristics (Bolaños et al., 2015; Santa Chávez et al., 2015; Gatica et al., 2016; Escobar-Falcón et al., 2021) and metaheuristics (EscobarFalcón et al., 2016).

\section{References}

Ashrae (2017). ASHRAE handbook of fundamentals. American Society of Heating. New York, pp. 24.1-24.6.

Aydemir, E., \& Karagul, K. (2020). Solving a Periodic Capacitated Vehicle Routing Problem Using Simulated Annealing Algorithm for a Manufacturing Company. Brazilian Journal of Operations \& Production Management, 17(1), 1-13.

Baker, B. M., \& Ayechew, M. A. (2003). A genetic algorithm for the vehicle routing problem. Computers \& Operations Research, 30(5), 787-800.

Bell, J. E., \& McMullen, P. R. (2004). Ant colony optimization techniques for the vehicle routing problem. Advanced Engineering Informatics, 18(1), 41-48.

Bernal, J., Escobar, J. W., \& Linfati, R. (2017). A granular tabu search algorithm for a real case study of a vehicle routing problem with a heterogeneous fleet and time windows. Journal of Industrial Engineering and Management, 10(4), 646662.

Bernal, J., Escobar, J. W., Paz, J. C., Linfati, R., \& Gatica, G. (2018). A probabilistic granular tabu search for the distance constrained capacitated vehicle routing problem. International Journal of Industrial and Systems Engineering, 29(4), 453477. 
Bolaños, R., Echeverry, M., \& Escobar, J. (2015). A multiobjective non-dominated sorting genetic algorithm (NSGA-II) for the Multiple Traveling Salesman Problem. Decision Science Letters, 4(4), 559-568.

Ceschia, S., Di Gaspero, L., \& Meneghetti, A. (2020). Extending and Solving the Refrigerated Routing Problem. Energies, 13(23), 6214.

Chávez, J., Escobar, J., \& Echeverri, M. (2016). A multi-objective Pareto ant colony algorithm for the Multi-Depot Vehicle Routing problem with Backhauls. International Journal of Industrial Engineering Computations, 7(1), 35-48.

Chen, L., Liu, Y., \& Langevin, A. (2019). A multi-compartment vehicle routing problem in cold-chain distribution. Computers \& Operations Research, 111, 58-66.

Cordeau, J. F., Gendreau, M., \& Laporte, G. (1997). A tabu search heuristic for periodic and multi-depot vehicle routing problems. Networks: An International Journal, 30(2), 105-119.

Eksioglu, B., Vural, A. V., \& Reisman, A. (2009). The vehicle routing problem: A taxonomic review. Computers \& Industrial Engineering, 57(4), 1472-1483.

Escobar, J. W., \& Linfati, R. (2012). Un algoritmo metaheurístico basado en recocido simulado con espacio de búsqueda granular para el problema de localización y ruteo con restricciones de capacidad. Revista Ingenierías Universidad de Medellín, 11(21), 139-150.

Escobar, J. W., Linfati, R., \& Toth, P. (2013). A two-phase hybrid heuristic algorithm for the capacitated location-routing problem. Computers \& Operations Research, 40(1), 70-79.

Escobar, J. W., Linfati, R., Baldoquin, M. G., \& Toth, P. (2014a). A Granular Variable Tabu Neighborhood Search for the capacitated location-routing problem. Transportation Research Part B: Methodological, 67, 344-356.

Escobar, J. W., Linfati, R., Toth, P., \& Baldoquin, M. G. (2014b). A hybrid granular tabu search algorithm for the multi-depot vehicle routing problem. Journal of Heuristics, 20(5), 483-509.

Escobar-Falcón, L. M., Álvarez-Martínez, D., Granada-Echeverri, M., Escobar, J. W., \& Romero-Lázaro, R. A. (2016). A matheuristic algorithm for the three-dimensional loading capacitated vehicle routing problem (3L-CVRP). Revista Facultad de Ingeniería Universidad de Antioquia, 78, 09-20.

Escobar-Falcón, L., Álvarez-Martínez, D., Wilmer-Escobar, J., \& Granada-Echeverri, M. (2021). A specialized genetic algorithm for the fuel consumption heterogeneous fleet vehicle routing problem with bidimensional packing constraints. International Journal of Industrial Engineering Computations, 12(2), 191-204.

Gatica, G., Villagrán, G., Bolton, C. C., Linfati, R., \& Escobar, J. W. (2016). A New Genotype-Phenotype Genetic Algorithm for the Two-Dimensional Strip Packing Problem with Rotation of 90 1. Ingenieria y universidad, 20(1), 119-138.

Gendreau, M. (2003). An introduction to tabu search. In Handbook of metaheuristics, pp. 37-54. Springer, Boston, MA.

Hsu, C. I., \& Hung, S. F. (2003). Vehicle routing problem for distributing refrigerated food. Journal of the Eastern Asia Society for Transportation Studies, 5, 2261-2272.

Hsu, C. I., Hung, S. F., \& Li, H. C. (2007). Vehicle routing problem with time-windows for perishable food delivery. Journal of Food Engineering, 80(2), 465-475.

James, S. J., Swain, M. J., Brown, T., Evans, J. A., Tassou, S. A., Ge, Y. T., ... \& Baglee, D. (2009). Improving the energy efficiency of food refrigeration operations. In Proceedings of the Institute of Refrigeration, Vol. 5.

Kara, I., Kara, B. Y., \& Yetis, M. K. (2007). Energy minimizing vehicle routing problem. In International Conference on Combinatorial Optimization and Applications (pp. 62-71). Springer, Berlin, Heidelberg.

Karagul, K., Sahin, Y., Aydemir, E., \& Oral, A. (2019). A simulated annealing algorithm based solution method for a green vehicle routing problem with fuel consumption. In Lean and green supply chain management, pp. 161-187. Springer, Cham.

Lepri, S., Livi, R., \& Politi, A. (2003). Thermal conduction in classical low-dimensional lattices. Physics Reports, 377(1), 180.

Li, G. (2017). Comprehensive investigation of transport refrigeration life cycle climate performance. Sustainable Energy Technologies and Assessments, 21, 33-49.

Li, Y., Soleimani, H., \& Zohal, M. (2019). An improved ant colony optimization algorithm for the multi-depot green vehicle routing problem with multiple objectives. Journal of Cleaner Production, 227, 1161-1172.

Linfati, R., Escobar, J. W., \& Gatica, G. (2014). Un algoritmo metaheurístico para el problema de localización y ruteo con flota heterogénea. Ingeniería y Ciencia, 10(19), 55-76.

Liu, G., Hu, J., Yang, Y., Xia, S., \& Lim, M. K. (2020). Vehicle routing problem in cold Chain logistics: A joint distribution model with carbon trading mechanisms. Resources, Conservation and Recycling, 156, 104715.

Meneghetti, A., Da Rold, G., \& Cortella, G. (2018). Sustainable refrigerated food transport: searching energy efficient routes. IFAC-PapersOnLine, 51(11), 618-623.

Meneghetti, A., \& Ceschia, S. (2020). Energy-efficient frozen food transports: The refrigerated routing problem. International Journal of Production Research, 58(14), 4164-4181.

Novaes, A. G., Lima Jr, O. F., Carvalho, C. C. D., \& Bez, E. T. (2015). Thermal performance of refrigerated vehicles in the distribution of perishable food. Pesquisa Operacional, 35(2), 251-284.

Osman, I. H. (1993). Metastrategy simulated annealing and tabu search algorithms for the vehicle routing problem. Annals of Operations Research, 41(4), 421-451.

Osvald, A., \& Stirn, L. Z. (2008). A vehicle routing algorithm for the distribution of fresh vegetables and similar perishable food. Journal of Food Engineering, 85(2), 285-295. 
Prajapati, V. K., Jain, M., \& Chouhan, L. (2020). Tabu search algorithm (TSA): A comprehensive survey. In 2020 3rd International Conference on Emerging Technologies in Computer Engineering: Machine Learning and Internet of Things (ICETCE) (pp. 1-8). IEEE.

Prosen, T., \& Robnik, M. (1992). Energy transport and detailed verification of Fourier heat law in a chain of colliding harmonic oscillators. Journal of Physics A: Mathematical and General, 25(12), 3449.

Puenayán, D. E., Londoño, J. C., Escobar, J. W., \& Linfati, R. (2014). Un algoritmo basado en búsqueda tabú granular para la solución de un problema de ruteo de vehículos considerando flota heterogénea. Revista Ingenierías Universidad de Medellin, 13(25), 81-98.

Rai, A., \& Tassou, S. A. (2017). Energy demand and environmental impacts of alternative food transport refrigeration systems. Energy Procedia, 123, 113-120.

Santa Chávez, J. J., Echeverri, M. G., Escobar, J. W., \& Meneses, C. A. P. (2015). A metaheuristic ACO to solve the multidepot vehicle routing problem with backhauls. International Journal of Industrial Engineering and Management (IJIEM), 6(2), 49-58.

Song, B. D., \& Ko, Y. D. (2016). A vehicle routing problem of both refrigerated-and general-type vehicles for perishable food products delivery. Journal of Food Engineering, 169, 61-71.

Tang, Y., \& Huang, G. (2018). Vehicle Routing Problem for perishable food in Cold Chain with Fuzzy Time Windows. In 2018 International Conference on Mathematics, Modelling, Simulation and Algorithms (MMSA 2018), pp. $361-367$. Atlantis Press

Tarantilis, C. D., \& Kiranoudis, C. T. (2001). A meta-heuristic algorithm for the efficient distribution of perishable foods. Journal of Food Engineering, 50(1), 1-9.

Tassou, S. A., De-Lille, G., \& Ge, Y. T. (2009). Food transport refrigeration-Approaches to reduce energy consumption and environmental impacts of road transport. Applied Thermal Engineering, 29(8-9), 1467-1477.

Tassou, S. A., Lewis, J. S., Ge, Y. T., Hadawey, A., \& Chaer, I. (2010). A review of emerging technologies for food refrigeration applications. Applied Thermal Engineering, 30(4), 263-276.

Toth, P., \& Vigo, D. (2003). The granular tabu search and its application to the vehicle-routing problem. Informs Journal on Computing, 15(4), 333-346.

Villagra, S., Villagra, A., Lasso, M. G., Pandolfi, D., San Pedro, M. E. D., Rasjido, J., ... \& Miño, R. (2011). Metaheurísticas aplicadas al Problema de Ruteo de Vehículos. In XIII Workshop de Investigadores en Ciencias de la Computación.

Wang, S., Tao, F., Shi, Y., \& Wen, H. (2017). Optimization of vehicle routing problem with time windows for cold chain logistics based on carbon tax. Sustainability, 9(5), 694.

Wu, X., Hu, S., \& Mo, S. (2013). Carbon footprint model for evaluating the global warming impact of food transport refrigeration systems. Journal of Cleaner Production, 54, 115-124.

Xia, Y., \& Fu, Z. (2019). A tabu search algorithm for distribution network optimization with discrete split deliveries and soft time windows. Cluster Computing, 22(6), 15447-15457.

Xu, S. H., Liu, J. P., Zhang, F. H., Wang, L., \& Sun, L. J. (2015). A combination of genetic algorithm and particle swarm optimization for vehicle routing problem with time windows. Sensors, 15(9), 21033-21053.

Yumrutaş, R., Kunduz, M., \& Kanoğlu, M. (2002). Exergy analysis of vapor compression refrigeration systems. Exergy, An International Journal, 2(4), 266-272.

Zanoni, S., \& Zavanella, L. (2012). Chilled or frozen? Decision strategies for sustainable food supply chains. International Journal of Production Economics, 140(2), 731-736.

Zhang, G., Habenicht, W., \& Spieß, W. E. L. (2003). Improving the structure of deep frozen and chilled food chain with tabu search procedure. Journal of Food Engineering, 60(1), 67-79.

Zhang, Y., \& Chen, X. D. (2014). An optimization model for the vehicle routing problem in multi-product frozen food delivery. Journal of Applied Research and Technology, 12(2), 239-250.

Zhao, Z., Li, X., \& Zhou, X. (2020). Optimization of transportation routing problem for fresh food in time-varying road network: Considering both food safety reliability and temperature control. PloS one, 15(7), e0235950. 
(C) 2022 by the authors; licensee Growing Science, Canada. This is an open access article distributed under the terms and conditions of the Creative Commons Attribution (CCBY) license (http://creativecommons.org/licenses/by/4.0/). 